\title{
INVESTIGATION OF COMPRESSIBLE FLOW THROUGH A TURBINE BLADE CASCADE FOR VARIOUS TRANSONIC FLOW REGIMES
}

\author{
Petr Louda ${ }^{a, *}$, JARomír Příhoda ${ }^{b}$, PAVEl ŠAfaříK ${ }^{a}$ \\ ${ }^{a}$ Czech Technical University in Prague, Faculty of Mechanical Engineering, Karlovo nám. 13, 12135 Praha, \\ Czech Republic \\ ${ }^{b}$ Institute of Thermomechanics of the Czech Academy of Sciences, Dolejškova 5, 18200 Praha, Czech Republic \\ * corresponding author: petr.louda@fs.cvut.cz
}

\begin{abstract}
This paper deals with the numerical simulation of 2D transonic flow through the SE1050 turbine blade cascade at various flow conditions. The first one concerns the design operation with a zero incidence angle involved in the ERCOFTAC Database CFD-QNET and the second one with a $+20^{\circ}$ incidence angle corresponding to an off-design operation. Advanced mathematical models with two different models of the bypass transition to turbulence were applied for the simulation of different regimes of transonic flows as well as with attached and separated flows. Transition models proposed by Dick et al. [1] and by Menter and Smirnov [2] are based on transport equations for the intermittency coefficient. Numerical results were compared with experimental data based on the optical and pressure measurements.
\end{abstract}

KEYworDs: Transonic flow, turbine blade cascade, numerical simulations, transition.

\section{INTRODUCTION}

Compressible flow in turbomachines belongs to most of the complicated tasks of fluid dynamics in practical applications. It follows from the complicated geometry of flow channels, especially blade cascades, and from the three-dimensional character of flow with a significant effect of secondary flows. The transonic flow through the turbine blade cascades is influenced particularly by the interaction of shock waves with shear layers developing on blades. The effect of laminar/turbulent transition and heat transfer should be considered in simulations. These processes are influenced by the flow turbulence and wall roughness as well. The flow structure in the blade cascade depends largely on the character of the shock-wave/boundary layer interaction. In the case of the interaction with the laminar boundary layer, the flow separation usually comes about after the transition to a separated flow. This results in the growth of the boundary thickness and the loss of a coefficient. The experimental and numerical investigation of compressible flows in blade cascades is, therefore, central from a viewpoint of the basic research and technical applications.

The flexibility of turbomachine operations is one of the topical problems for research and development of machines. Until now, turbomachines have been designed and operated to run as smoothly as possible under full load conditions with adequate efficiency. The increasing duration of the partial load or overload operation needs a new approach for turbomachine development and design. The aerodynamic research oriented to modeling flow processes in turbomachines should be more aimed to provide data on partial load and overload operation, namely of high loaded turbine stages.

The typical turbine rotor blade cascade SE1050 has been investigated at various flow conditions in a wide range of Mach numbers and incidence angles including high positive and negative values (Štastný and Šafařík [3, 4]). Data related to the design operation are included as a test case in the ERCOFTAC Database CFD-QNET, see Příhoda and Kozel [5]. Similarly, until now numerical simulations have been carried out by means of mathematical models based on turbulence models and/or simple transition models (see e.g. Dobeš et al. [6], Šafařík et al. [7]). Furthermore, the experimental and numerical investigation of the 3D flow through the prismatic blade cascade has been realised, see Šimurda et al. [8]. The research was focused on the effect of the inlet velocity distribution on flow structures in the interblade channel and on flow field parameters. Numerical simulations were carried out by the SST turbulence model.

The presented numerical simulations are focused on the application of advanced mathematical models including the laminar/turbulent transition models for different regimes of transonic flows. Two transition models proposed by Dick et al. 1 and Menter and Smirnov 2 based on the transport equations for the intermittency coefficient were chosen for simulation of two flow conditions - the first one with a 0 incidence angle and the second one with the incidence angle $\iota=+20^{\circ}$ which corresponds to an overload operation. 


\begin{tabular}{ll}
\hline chord $c$ & $100 \mathrm{~mm}$ \\
pitch/chord $s / c$ & 0.551 \\
stagger angle $\gamma$ & $37.11^{\circ}$ \\
nominal inlet angle $\alpha_{1}$ & $19.3^{\circ}$ \\
nominal incidence angle $\iota$ & $0^{\circ}$ \\
nominal exit Mach number $M_{2 i s}$ & 1.2 \\
\hline
\end{tabular}

TABle 1. Characteristic dimensions of the blade cascade.

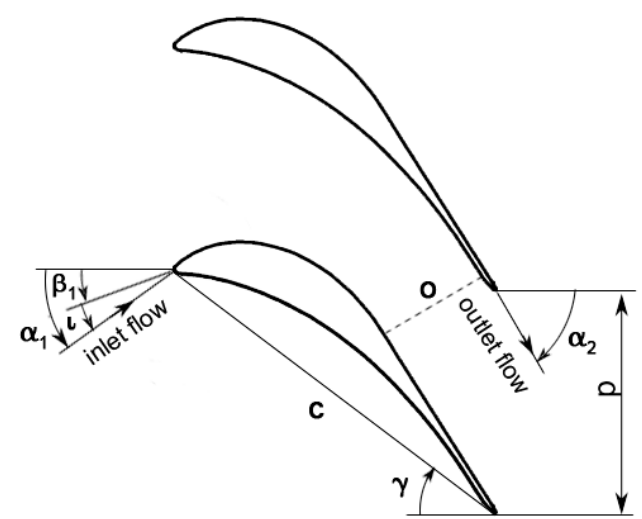

Figure 1. Scheme of the SE1050 blade cascade.

\section{EXPERIMENTS}

The chosen rotor blade cascade SE 1050 was designed for the last stage of a steam turbine of large output with the blade length $1,085 \mathrm{~mm}$, a nominal speed of 3,000 rpm and operating at transonic velocities. The SE1050 profile is a section view of a rotor blade at the distance $320 \mathrm{~mm}$ from the root. The blade cascade was designed for the inlet flow angle $\alpha_{1}=19.3^{\circ}$ and the isentropic exit Mach number $M_{2 i s}=1.208$. Characteristic dimensions of the blade cascade are given in Table 1. The scheme of the turbine blade cascade is shown in Fig. 1 .

The experimental investigation of compressible flow through the blade cascade was realized in the suctiontype high-speed wind tunnel located at the Aerodynamic Laboratory of the Institute of Thermomechanics AS CR in Nový Knín. The experimental facility provides the possibility of pneumatic and optical measurements in the range of exit Mach numbers up to $M_{2} \approx 2$.

The optical and pressure measurements were carried out in a wide range of boundary conditions starting with the design operation up to the off-design operations with extensive separation, see Štastný and Šafař́́k [3, 4. Optical measurements were carried out by the Mach-Zehnder interferometer and pressure measurements by the Prandtl probe upstream the blade cascade and by the five-hole conical probe in the traversing plane behind the blade cascade. With the measuring equipment, it is possible to measure the loss coefficient $\xi$ with the absolute uncertainty less than $0.4 \%$ and the outlet angle $\alpha_{2}$ with the uncertainty less than $1^{\circ}$. The data reduction method proposed by Amecke and Šafařík [9] was used for the evaluation of the experimental data as well as for the results of CFD simulations.

The compressible flow though the blade cascade was measured in the $2 \mathrm{D}$ basic configuration at the inlet flow angle $\alpha_{1}=19.3^{\circ}$, the outlet isentropic Mach number $M_{2 i s}=1.198$ and the Reynolds number $R e_{2 i s}=1.48 \times 10^{6}$. Further measurements were carried out for the exit Mach number in the range $M_{2 i s} \in(0.489 ; 1.387)$. Some additional experiments were carried out for extreme values of incidence covering the range from very small loading to overloading conditions.

\section{Mathematical MOdel}

Governing equations, describing the flow of viscous compressible fluid, are given by the Favre-averaged conservative laws of mass, momentum and energy

$$
\begin{gathered}
\frac{\partial \rho}{\partial t}+\frac{\partial\left(\rho U_{i}\right)}{\partial x_{i}}=0 \\
\frac{\partial\left(\rho U_{i}\right)}{\partial t}+\frac{\partial\left(\rho U_{i} U_{j}\right)}{\partial x_{j}}=-\frac{\partial p}{\partial x_{i}}+\frac{\partial}{\partial x_{j}}\left(t_{i j}+\tau_{i j}\right) \\
\frac{\partial(\rho e)}{\partial t}+\frac{\partial}{\partial x_{j}}\left[U_{j}(\rho e+p)\right]= \\
=\frac{\partial}{\partial t}\left[U_{i}\left(t_{i j}+\tau_{i j}\right)+\left(\frac{\mu}{\operatorname{Pr}}+\frac{\mu_{t}}{\operatorname{Pr}_{t}}\right) \frac{\partial h}{\partial x_{j}}\right]
\end{gathered}
$$

where $\rho$ is the density; $U_{i}$ are the components of the velocity vector; $p$ is the static pressure; $e$ is the specific total energy; $h=e+p-U_{i} U_{i} / 2$ is the specific total enthalpy; $t_{i j}$ is the mean viscous stress tensor; $\tau_{i j}$ is the Reynolds stress tensor; $\mu$ is the molecular viscosity; $\mu_{t}$ is the turbulent viscosity; Pr is the Prandtl number; lastly, $\mathrm{Pr}_{t}$ is the turbulent Prandtl number. A simple turbulent heat transfer model $\operatorname{Pr}_{t}=0.9$ is used. This system of governing equations is completed by constitutive relations, especially by the state equation, by the Sutherland's relation for the viscosity and by the transition model.

Two bypass transition models based on transport equations for the intermittency coefficient were used. The $\gamma$ transition model proposed by Menter and Smirnov 22 is the simplified $\gamma-R e_{\theta}$ model of Langtry and Menter 10 with one transport equation for the intermittency coefficient

$$
\begin{aligned}
\frac{\partial(\rho \gamma)}{\partial t}+ & \frac{\partial\left(\rho U_{j} \gamma\right)}{\partial x_{j}}= \\
& =P_{\gamma}-E_{\gamma}+\frac{\partial}{\partial x_{j}}\left[\left(\mu+\frac{\mu_{t}}{\sigma_{\gamma}}\right) \frac{\partial \gamma}{\partial x_{j}}\right]
\end{aligned}
$$

The production term is given by the relation

$$
P_{\gamma}=F_{\text {length }} \rho S \gamma(1-\gamma) F_{\text {onset }}
$$

with empirical correlations $F_{\text {onset }}$ and $F_{\text {length }}$ for the transition onset and length. The destruction term 
enables the prediction of the relaminarization and is defined by the equation

$$
E_{\gamma}=C_{a 2} \rho \Omega \gamma F_{t u r b}\left(C_{e 2} \gamma-1\right)
$$

Values $S$ and $\Omega$ are the strain rate magnitude and the vorticity rate, respectively.

The $\gamma-\zeta$ intermittency model of Dick et al. [1 splits the intermittency into near wall part $\gamma$ and freestream part $\zeta$. The corresponding transport equations read

$$
\begin{aligned}
& \frac{\partial(\rho \gamma)}{\partial t}+\frac{\partial\left(\rho U_{i} \gamma\right)}{\partial x_{i}}=S_{\gamma}+\frac{\partial}{\partial x_{i}}\left[\left(\mu+\sigma_{\gamma} \mu_{t}\right) \frac{\partial \gamma}{\partial x_{i}}\right] \\
& \frac{\partial(\rho \zeta)}{\partial t}+\frac{\partial\left(\rho U_{i} \zeta\right)}{\partial x_{i}}=S_{\zeta}+\frac{\partial}{\partial x_{i}}\left[\left(\mu+\sigma_{\zeta} \mu_{\zeta}\right) \frac{\partial \zeta}{\partial x_{i}}\right]
\end{aligned}
$$

with source terms

$$
\begin{gathered}
S_{\gamma}=2 \beta_{\lambda}(1-\gamma) \sqrt{-\ln (1-\gamma)} \rho U_{\gamma} F_{s} \\
S_{\zeta}=-C_{2} \mu_{\zeta} \frac{U}{U_{e}^{2}} \frac{\partial U}{\partial n} \frac{\partial \zeta}{\partial n}
\end{gathered}
$$

where $\mu_{\zeta}$ is the viscosity for $\zeta, \beta_{\gamma}$ growth parameter, $U_{\gamma}$ the mean velocity scale, $n$ the wall-normal direction and coefficients $\sigma_{\gamma}=\sigma_{\zeta}=1$. The source term $S_{\zeta}$ guarantees that $\zeta$ vanishes in the boundary layer. For more details see the corresponding references [1, 2].

Both used transition models are coupled with the SST turbulence model, see Menter [11. The production terms in the SST model is limited by the Medic-Durbin limiter in the $\gamma-\zeta$ model, while in the Menter-Smirnov $\gamma$ model it uses the Kato-Launder formulation mixed of strain rate and rotation rate.The criterion for the transition on separation in the $\gamma-\zeta$ model is re-formulated in order to remove non-local upstream dependence.

The system of averaged Navier-Stokes, turbulence model and transition model equations is solved by an implicit upwind finite volume method. The finite volumes are quadrilateral shapes. The inviscid flux is computed using the AUSMPW + method with second order interpolation and the van Leer limiter. Viscous fluxes are computed on dual finite volume grid by the second order central scheme. The time discretization is accomplished by the implicit Euler method with linearization leading to a block 5 -diagonal system. The linear solver is a combination of the direct 3-diagonal solver and the relaxation iterative method.

The computational domain shown in Fig. 2 is formed by one pitch of the blade cascade with the inlet part extending about one half of the pitch upstream the leading edge plane and the outlet part extending about one pitch downstream the trailing edge plane. The grid for one period of the blade cascade consists of 9 structured blocks of quadrilateral cells. The density of the mesh was chosen according to the mesh sensitivity test made by Váchová et al. [12] for a similar blade cascade. The details of the grid near the leading edge is given in Fig. 3 The O-grid is constructed

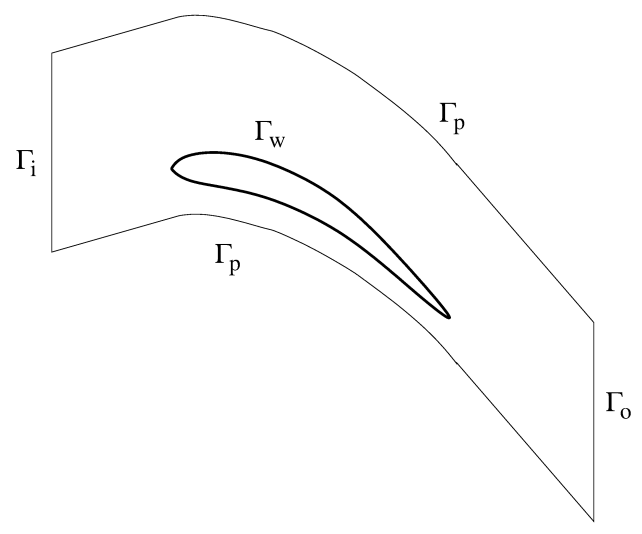

FIgURE 2. Scheme of the computational domain.

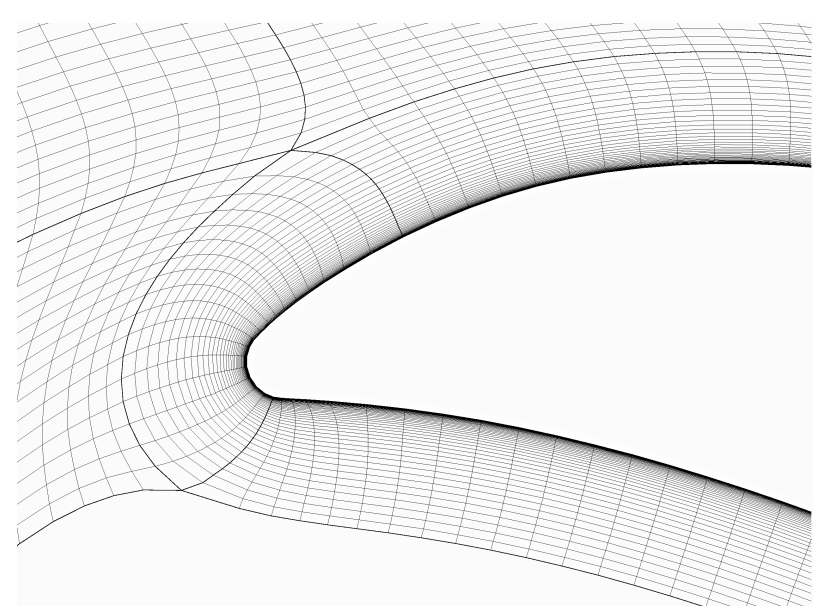

Figure 3. Detail of the grid.

around the blade with 210 grid points on the blade. The minimum cell thickness is $0.003 \mathrm{~mm}$ for the first 5 steps then the steps are stretched further from the blade. The grid has about 22,500 cells in total. The distance to the nearest cell-centre from the wall is $n^{+} \approx 0.5$.

The inlet boundary conditions are prescribed by the total pressure, total temperature and inlet flow angle. The inlet free-stream turbulence was set $T u=$ $2 \%$ and the inlet specific dissipation rate is given by the turbulent Reynolds number $R e_{t}=200$. The outlet boundary condition is defined by the mean value of the static pressure according to the outlet isentropic Mach number by means of the non-reflecting condition. The adiabatic and smooth wall of the blade is considered. Periodicity conditions were used on the side boundaries of the computation domain.

\section{Results}

The numerical simulations were carried out for two different flow conditions. The first one is the design operation e with the outlet isentropic Mach number $M_{2 i s}=1.198$, inlet Mach number $M_{1}=0.375$, the Reynolds number $R e_{2 i s}=1.48 \times 10^{6}$ and a zero incidence angle. Corresponding to an overload operation, the second simulation uses the values $M_{2 i s}=1.184$, 


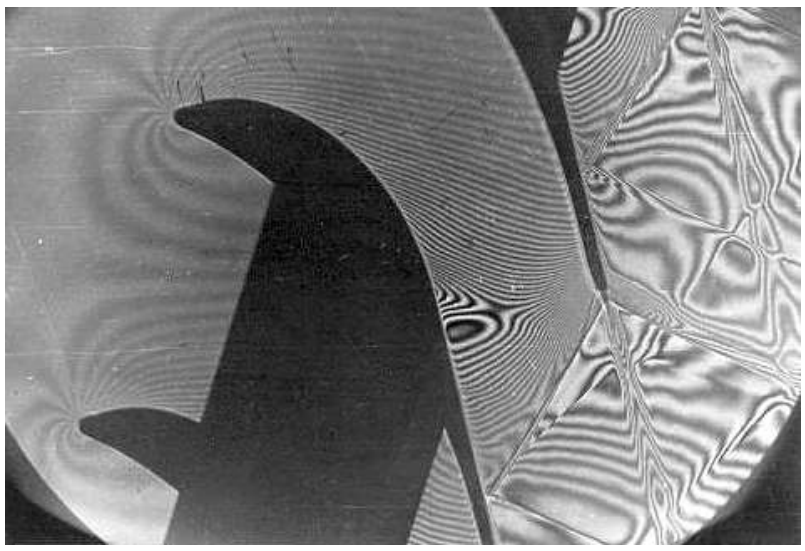

FiguRE 4. Interferometric picture for the design operation.

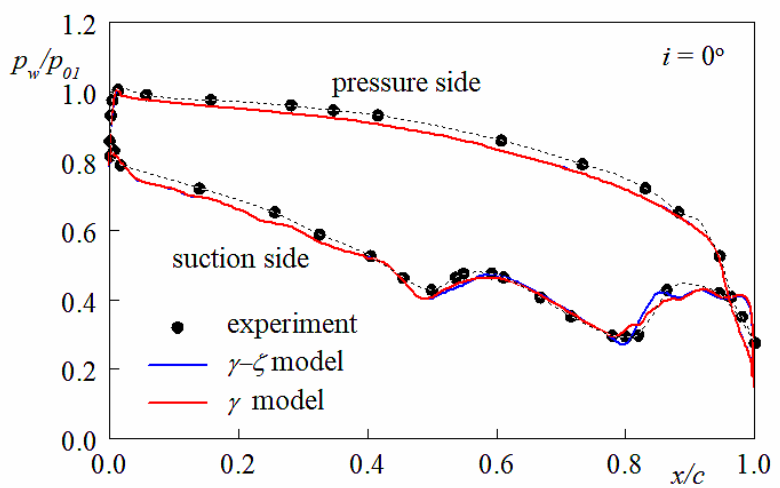

Figure 5. Distribution of the static pressure on the blade for the design operation.

$M_{1}=0.451, R e_{2 i s}=1.52 \times 10^{6}$ and with the incidence angle $\iota=+20^{\circ}$.

\subsection{Design Operation}

The interferogram of the flow field in the blade cascade at the design operation is shown in Fig. 4. The inlet velocity is subsonic and the flow in the interblade channel is accelerated. The acceleration on the pressure side is monotonic. Near the throat the speed of sound is reached. Further expansion into supersonic velocities leads to a decrease and subsequent increase of the flow velocity on the suction side. The phenomenon of local supersonic compression accompanying the transonic expansion appears. The theoretical analysis confirms that the compression effect is directly related to the curvature change on the suction side at the position $x / c=0.5$, see Straka et al. [13]. Transonic flow is very sensitive on sudden changes that influence the fluid-flow structure.

The distribution of the static pressure on the blade is shown in Fig. 5 The effect of the curvature change can be seen on the suction side in one half of the chord. The numerical results obtained by both transition models correspond very well with the experiment. After the supersonic compression, which accompanies the transonic expansion, the intensive supersonic ex- pansion occurs. This is terminated by the inner branch of the exit shock waves from the neighboring profile. This shock wave interacts with the boundary layer on the suction side at the distance $x / c \approx 0.8$, where the shock wave of the opposite family appears and the supersonic expansion is slowed down to become again more intensive before the trailing edge.

The field of Mach number isolines for the design operation is shown in Fig. 6. The subsonic flow is marked by blue colour and the supersonic by red colour. The isolines are scaled with a step $\Delta M=0.05$. Numerical simulations are very similar to experimental results. The sonic line and the interaction of the boundary layer on the suction side with the inner branch of exit shock wave from the neighboring profile are in accordance with the interferometric picture.

The character of the flow is also very well documented by the distribution of the skin friction coefficient along the blade shown in Fig. 7] While the boundary layer on the pressure side is laminar, the transition on the suction side occurs approximately at the position of the sudden curvature change. The interaction with the exit shock wave causes a relatively short separation region. The $\gamma-\zeta$ transition model predicts a higher skin friction coefficient than the $\gamma$ model.

\subsection{OfF-DESIGN OPERATION}

Corresponding to the overload operation, the interferogram of the flow field in the blade cascade at the incidence angle $\iota=+20^{\circ}$ is shown in Fig. 8. Due to the nonzero incidence, the stagnation point is moved to the leading part of the pressure side of the profile and the flow separation occurs on the leading edge of the suction side of the profile. The separation zone is evident in the interferogram because of a relative thick shear layer, but the reattachment point is not distinct. The acceleration of shear flow, which is downstream the separation zone, initiates from $x / c=0.25$. Again the velocity of sound is reached near the throat. The phenomenon of local supersonic compression accompanying the transonic expansion on the suction side of the profile seems to be more moderate in comparison to the design operation. It can be explained as an effect of the relatively thick shear layer. The nonsymmetric wave, which is downstream the trailing edge, is also a consequence of the shear layer acting as a dissipative structure. The increase of the kinetic energy loss coefficient from $4.6 \%$ to $5.8 \%$ is caused by the leading edge separation.

The distribution of the static pressure on the blade for the off-design operation is shown in Fig. 9. The monotonous decrease of static pressure on the pressure side is in good accordance with the flow development in the turbine blade channel for transonic flow at overload conditions. The pressure distribution on the suction side is affected by the flow separation on the leading edge. Also, for the off-design operation, the effect of the curvature change is apparent on the 


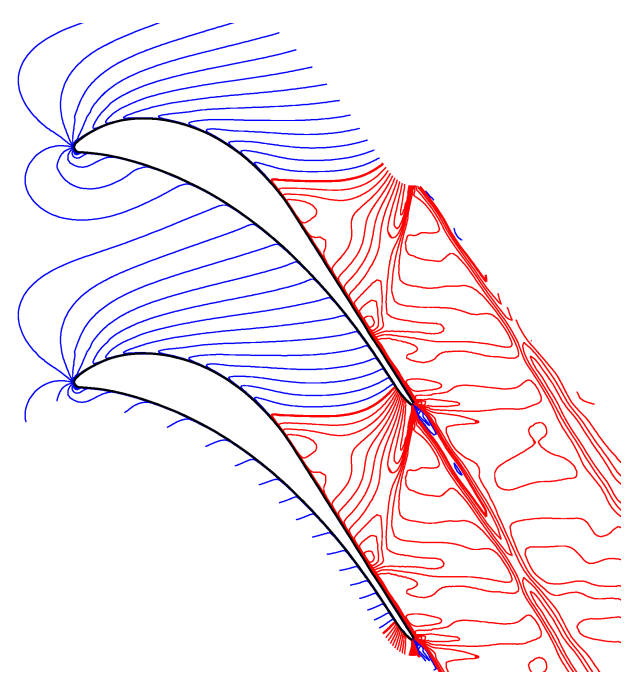

(A) $\cdot \gamma-\zeta$ model

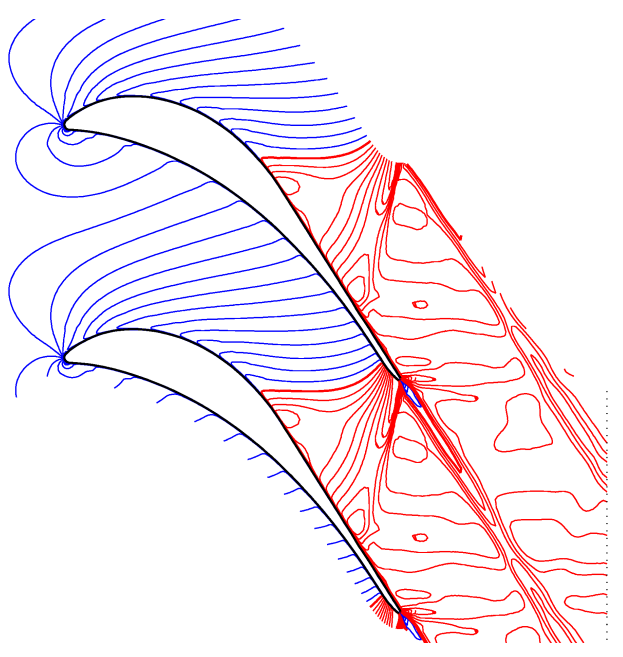

(в) $\cdot \gamma$ model

FiguRE 6. Mach number isolines in the blade cascade for the design operation.

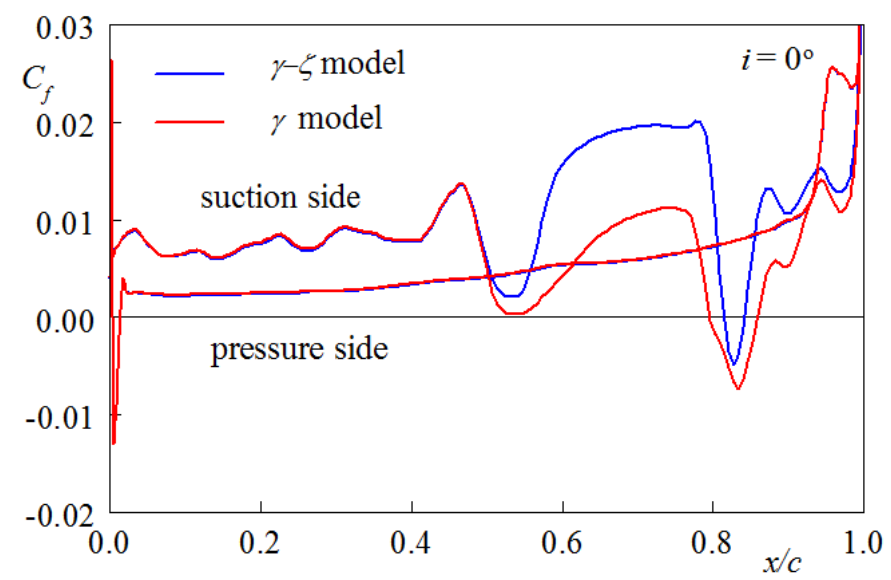

FiguRE 7. Distribution of the skin friction coefficient for the design operation.

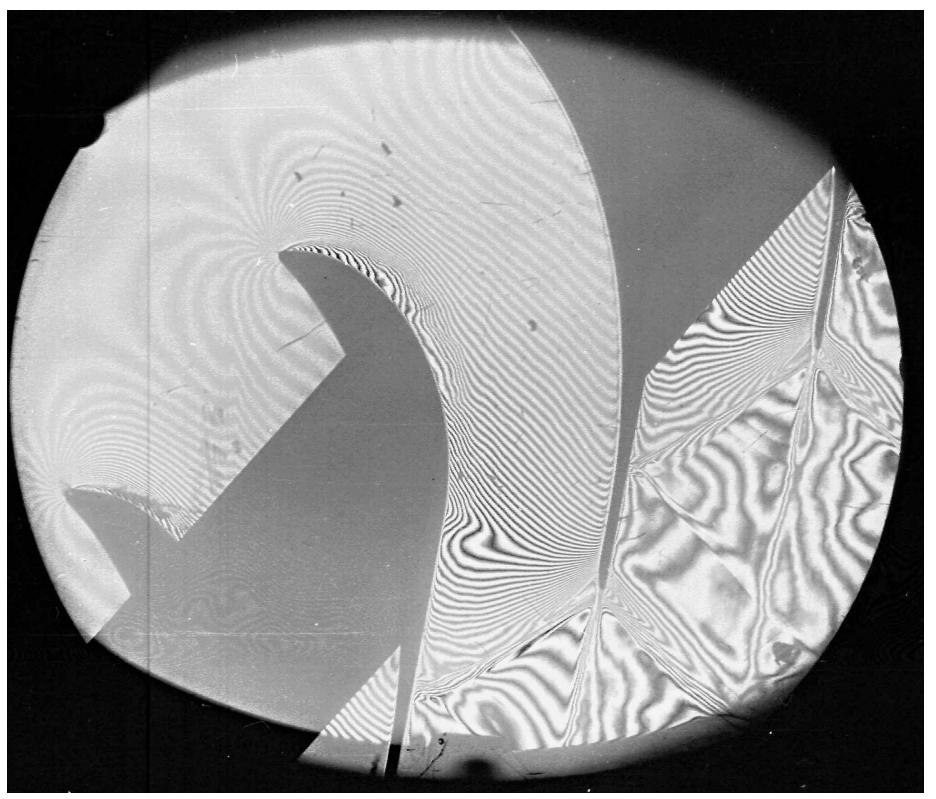

FIGURE 8. Interferometric picture for the off-design operation. 


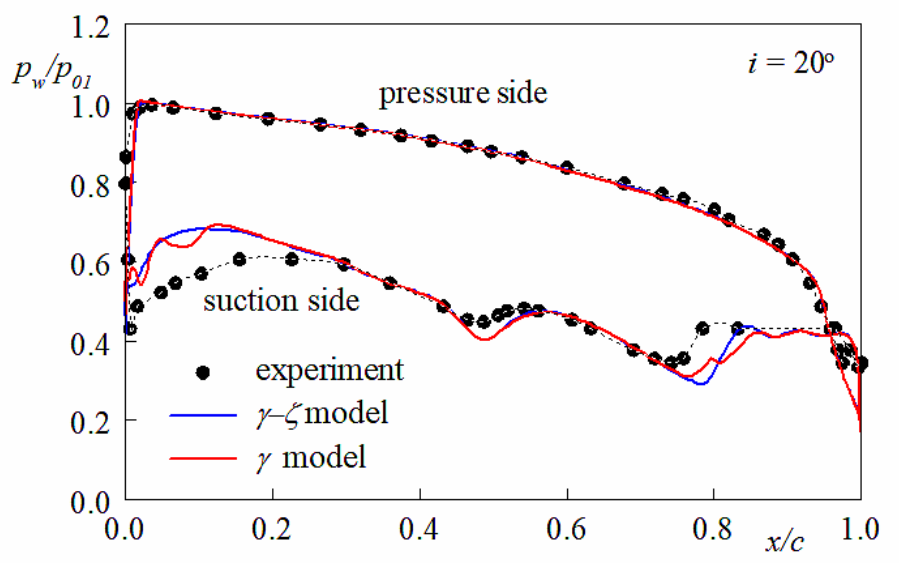

Figure 9. Distribution of the static pressure for the off-design operation.

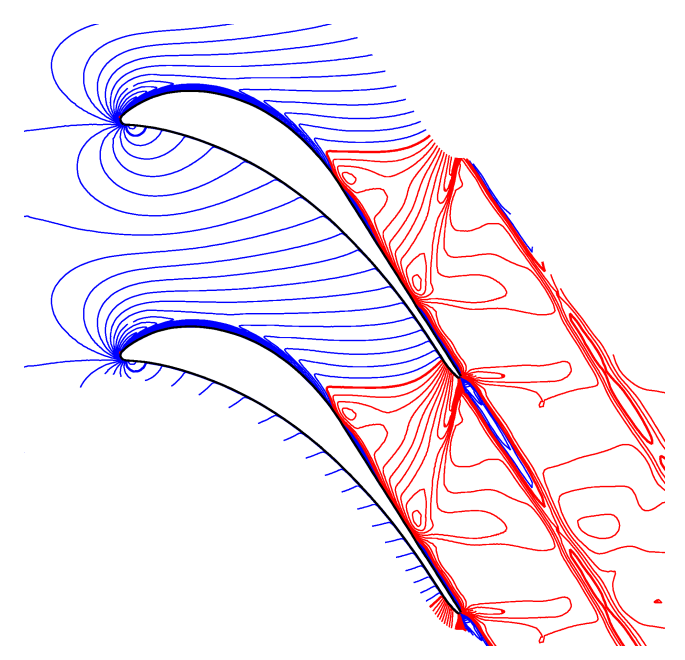

(A) $\cdot \gamma-\zeta$ model

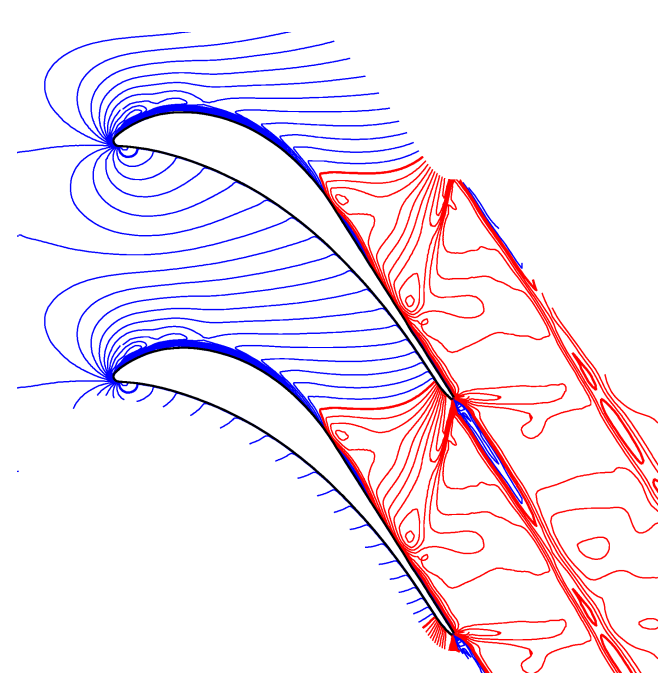

(B).$\gamma$ model

FiguRE 10. Mach number isolines in the blade cascade for the off-design operation.

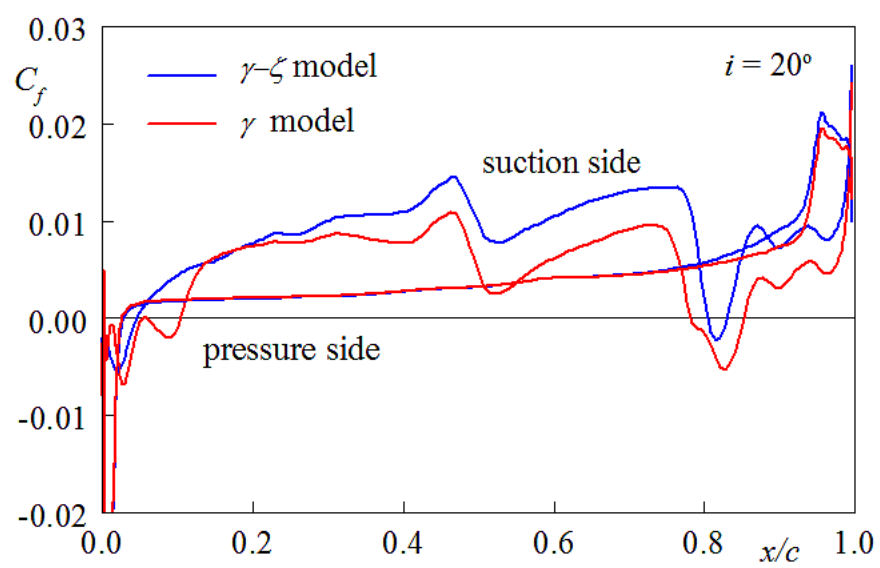

FiguRE 11. Distribution of the skin friction coefficient for the off-design operation. 
suction side. The position of the interaction of the exit shock wave with the boundary layer moves somewhat upstream in comparison with the design operation.

The field of Mach number isolines for the off-design operation is shown in Fig. 10. The field structure obtained by numerical simulation is again similar to experiment. The predicted separation zone near the leading edge is slightly shorter than what is seen in the interferogram. Numerical simulations predict a slightly different angle between the exit shock wave and the blade chord as can be seen on the pressure distribution in Fig. 9

The distribution of the skin friction coefficient is shown in Fig. 11 The boundary layer on the pressure side is laminar practically for the whole chord, but a separation zone is predicted by both transition models near the leading edge of the suction side even though the separation length obtained by the $\gamma-\zeta$ transition model is very short. The skin friction distribution then behaves similar to design inlet angle regime, i.e. one can see the effect of the sudden change of blade curvature and the interaction with the exit shock wave from the neighbouring blade.

\section{Conclusion}

The transonic flow through the turbine blade cascade SE1050 was investigated by two bypass transition models for design and off-design operations. Simulations were focused on the effect of the incidence angle on the flow structure in the blade cascade and the ability of used transition models to model adequately the transition in attached and separated flows. Both models are able to capture all significant phenomena of the transonic flow, as the effect of the sudden change of the blade curvature and the interaction of the shock wave with the laminar boundary layer, leading to the transition in separated flow. Unlike the $\gamma$ model of Menter and Smirnov [2], the $\gamma-\zeta$ model proposed by Dick et al. [1] is not based on fully local variables. Nevertheless, both transition models connected with the SST turbulence model provide an acceptable agreement with experimental results and can be used for the simulation of transonic flows in blade cascades with a complicated flow structure.

\section{ACKNOWLEDGEMENTS}

The work was supported by the Technology Agency of the Czech Republic under the National Centre for Power Engineering TH1000072. Institutional support RVO 61388998 is also gratefully acknowledged.

\section{REFERENCES}

[1] E. Dick, S. Kubacki, K. Lodefier, W. Elsner. Engineering applications of computational fluid dynamics, vol. 2, International Energy and Environment Foundation, chap. Intermittency modelling of transitional boundary layer flows on steam and gas turbine blades, pp. 173 - 216. 2012.
[2] F. R. Menter, P. E. Smirnov, T. Liu, R. Avancha. A one-equation local correlation-based transition model. Flow, Turbulence and Combustion 95:583 - 619, 2015. DOI:10.1007/s10494-015-9622-4.

[3] M. Štastný, P. Šafař́k. Experimental analysis data on the transonic flow past a plane turbine cascade. In Proceedings of the ASME 1990 International Gas Turbine and Aeroengine Congress and Exposition, vol. 1: Turbomachinery of Turbo Expo: Power for Land, Sea, and Air. 1990. DOI:10.1115/90-GT-313

[4] M. Štastný, P. Šafařík. Boundary layer effects on the transonic flow in a straight turbine cascade. In Proceedings of the ASME 1992 International Gas Turbine and Aeroengine Congress and Exposition, vol. 1: Turbomachinery of Turbo Expo: Power for Land, Sea, and Air. 1992. DOI:10.1115/92-GT-155

[5] J. Př́ihoda, K. Kozel. Steam turbine rotor cascade, AC 6-12. Tech. rep., ERCOFTAC QNET-CFD Database, 2004. http://qnet-ercoftac.cfms.org.uk/ w/index.php/AC_6-12_Description

[6] P. Šafařík, M. Štastný, M. Babák. Numerical and experimental testing of transonic flow in the etalon turbine cascade SE 1050. In G. Bois, M. Štastný, C. H. Sieverding (eds.), Proc. 5th European Conference on Turbomachinery, pp. 1007 - 1016. Prague, 2003.

[7] J. Dobeš, J. Fořt, J. Fürst, et al. Experimental and numerical analysis of transonic flow through plane turbine cascade. Engineering Mechanics 10:413 - 426, 2003.

[8] D. Šimurda, J. Fürst, M. Luxa. 3D flow past transonic turbine cascade SE 1050 - Experiment and numerical simulations. Journal of Thermal Science 22:311 - 319, 2013. DOI:10.1007/s11630-013-0629-7

[9] J. Amecke, P. Šafař́k. Data reduction of wake flow measurements with injection of another gas. DLR-Forschungsbericht 95-32, Göttingen, 1995.

[10] R. B. Langtry, F. R. Menter. Correlation-based transition modeling for unstructured parallelized computational fluid dynamics codes. AIAA Journal 47(12):2894 - 2906, 2009. DOI:10.2514/1.42362.

[11] F. R. Menter. Two-equation eddy-viscosity turbulence models for engineering applications. AIAA Journal 32(8):1598 - 1605, 1994. DOI:10.2514/3.12149.

[12] J. Váchová, M. Luxa, J. Př́íhoda, D. Šimurda. Transition model application on mid-section turbine blade cascade. In Proc. 12th International Symposium on Experimental Computational Aerothermodynamics of Internal Flows. Lerici, Italy, 2015.

[13] P. Straka, J. Př́ihoda, P. Šafařík. Prediction of boundary layer transition in transonic blade cascade with sudden change of surface curvature. In Proc. 18th International Scientific Conference Application of Experimental and Numerical Methods in Fluid Mechanics and Energy, pp. 261 - 268. Žilina, 2012. 